\title{
Perception towards Business Schools: A Three Dimensional View of Attitudes of Students, Management and Corporate Organizations of Karachi
}

\author{
Sajid Mehmood \\ Nawaz Ahmad
}

\begin{abstract}
This research is designed to assess the attitudes of undergraduate students, graduate students, faculties and corporate executives towards leading business schools of Karachi as per the standard of Higher Education Commission (HEC). Three different questionnaires were developed, to assess the attitude of students, management of institutions and corporate organizations towards the business schools. Data were collected and analyzed by using weighted average method from the respondent's answers to the questions. Quality of education is found to be the top most reason because of which students seeks admission. Majority of the students stated that faculty members may review method of teaching and level of cooperation in the class. Students are found dissatisfied with services of administration staff in institutes and with the existing career counseling facilities. Students further urged to fortify security arrangements at schools and to enhance indoor games facilities at the institutions. Management of the business institutes is found to be very much conscious about their grading and its implications on their reputation. Institutes are determined to improve their present ranking and the quality of education they impart. Most of them grade themselves as number one and suggests modifying HEC grading criterion by conducting surveys. Fifty percent of the corporate organizations graded attitude as the sole criteria for hiring a graduates. Ability of institutes for imparting education that fulfills the needs of modern business is recorded sixty three percent. Whereas efforts of business schools to incorporate inputs of corporate organization while designing academic activities is rated sixty percent. Conclusively, this research presents three dimensional view of the attitude of students, institutes and corporate organizations. The results of this research work are equally beneficial for the entire corporate community by helping them to identify grey areas in business education and aspirations of pertinent stakeholders.
\end{abstract}

Keywords: Attitude, Business Schools, Corporate community.

\section{Introduction}

Business education is one of the most effective means that a society possesses for encountering future challenges. The leading business schools are expected to provide a solid foundation to prepare students to meet this challenge.

Sajid Mehmood is working at Byco Petrolium Pakistan Ltd. as Logistics Officer, capt.sajidmehmood@gmail.com Nawaz Ahmad is a Ph.D. scholar and associated with Iqra University, Karachi, nawazahmad_pk@hotmail.com 
The business schools should provide an enabling requirement, conducive to scholarship and research. The faculty, staff, students and members of the industry should work together to achieve learning goals. Students acquire knowledge through constructive and distinctive process that encourages them to develop understanding of business concepts and issues, think independently and to make rational choices. They are encouraged to take responsibility for their own learning, to become active participants and leaders, and to apply their knowledge in real world context.

The salient features which students and employers look for in any business school education program is its emphasis on the application of knowledge acquired by the students for which conventional lecture method must be supplemented with case studies, problem solving, simulations and group discussions so that student attain in-depth knowledge of the realities of business world. This all is directly related to quality and standard of the faculty. Other factors like infrastructure, fees, library, and reputation of the school are equally important realities of the business world and are prepared to face them.

Under the directive of the ex-prime minister Shoukat Aziz, the Higher Education Commission developed the first ever 'Ranking of Universities' for Pakistan. Approved through a specialist Ranking Board constituted on by the Chairman of the HEC, the ranking methodology has been developed by the HEC Quality Assurance Committee (QAC) through a transparent consultative process in which various leading international ranking practices and systems were analyzed. The ranking model was developed by the QAC through extensive stakeholder participation, tailoring the process according to the ground realities of the higher education sector in Pakistan.

\section{Research Objective}

This research is designed to assess the attitudes of students, faculties and corporate executives towards leading business schools i.e. IBA, CBM, Hamdard, MAJU, SZABIST of Karachi as per the standard of HEC.

\subsection{Situation Analysis}

A decade ago, there were very limited business schools in Karachi but now there are 19 business schools in Karachi. While on the one hand this significant increase has provided opportunities to students who now have a wide array of choice, on the other hand, it has raised questions about the quality of education these institutions are imparting, their infrastructure, fees and the standard of faculty members. Popularly, it is assumed that business schools are meant to make money and to differentiate amongst social classes.

\subsection{Research Statement}

To present three dimensional view of the attitude towards business schools including students, corporate organization and management of business institutes. 


\section{Literature Review}

Morstain (1997) in his research work says that postsecondary institutions are faced with many questions regarding the value and effectiveness of their academic programs, heightened by the economic milieu of education and the rise of student consumerism. This study examined whether students' orientations regarding educational "purpose and process" and "relative fit" with faculty orientations were associated with students' satisfaction with their academic program. The findings suggested that dissatisfied students had educational orientation profiles noticeably divergent from peers moderately and highly satisfied. Moreover, dissatisfied students were least congruent with faculty while highly satisfied students had orientations most congruent with faculty. Further support was therefore advanced for a person-environment model in assessing student satisfaction, in this instance an environment shaped by faculty educational views. Discussion centered on various implications of student-faculty incongruence from both a student and an institutional perspective.

Scott (1986) wrote that the racial differences in the effects of intellectual and nonintellectual student characteristics and faculty attitudes and behaviors significantly predict students' college performance. Significant differences between black and white students' college performance and the predictors are discovered. Educators must address these differences to achieve equity in higher education.

Patterson (1996) empirically examines for the first time the determinants of customer satisfaction or dissatisfaction (CS/D) in the context of business professional services. The simultaneous effect of key CS/D constructs (expectations, performance, and disconfirmation) and several variables-fairness (equity), purchase situation (novelty, importance, and complexity)-and individual-level variables (decision uncertainty and stake holding) are examined in a causal path framework. Data were obtained from a two-stage longitudinal survey of client organizations. The results indicated substantial support for the hypothesized model. The effect of purchase situation and individual-level variables (via their indirect effects) rivals that of disconfirmation and expectations in explaining CS/D. Performance was found to affect CS/D directly but not as powerfully as disconfirmation.

Hodges (2003) studied New Zealand employers' views of how well business graduates are prepared for the workplace. The employers were asked to rate the importance of a selection of graduate competencies using a seven-point Likert scale, and were asked to rate new graduates' performance for the same graduate competencies. The study also investigated the level of importance that employers place on prior work experience for new business graduates. A'competency gap' between importance and performance was identified from these findings and the impact these findings have for cooperative education programs is discussed.

Stewart (2000) opines that research provides support for the view that HEls have a role in developing both "self-awareness" and "opportunity awareness" within undergraduates to support their ability to demonstrate employability in a changing labor market. As part of this, a focus on providing opportunities to develop transferable skills through the curriculum of degree programmes is argued to be appropriate and some examples are 
given. Suggested actions for students and SMEs, as well as HEls, are included to respond to the changing nature of graduate careers. Areas of further research are identified, and a conceptual model to inform such research is offered.

Gutteridge (1973) studied factors related to the career progress of graduate business school alumni. Individuals with full-time work experience prior to enrolling are progressing faster in their careers. Alumni employed in the engineering-production function are earning lower salaries. There is a negative relationship between company size and salaries. Alumni who have changed functional areas or employers are receiving higher salaries.

Oliver (1997) in his research suggests that the context and process of resource selection have an important influence on firm heterogeneity and sustainable competitive advantage. It is argued that a firm's sustainable advantage depends on its ability to manage the institutional context of its resource decisions. A firm's institutional context includes its internal culture as well as broader influences from the state, society, and firm relations that define socially acceptable economic behavior. A process model of firm heterogeneity is proposed that combines the insights of a resource-based view with the institutional perspective from organization theory.

Hernandez (2000) in his research wrote that approximately 54 million non institutionalized Americans have physical, intellectual, or psychiatric disabilities. Of these cases, 26 million are classified as having a severe disability (US Bureau of the Census, 1999). Severe disabilities include Alzheimer's disease, autism, mental retardation, and longterm use of a cane, crutches, walker, or wheelchair. Historically, individuals with disabilities have not fared well in the US labor force (Braddock \& Bachelder, 1994). Census figures indicate that of the 15.6 million working-age adults with disabilities (aged 16-64), only $34.6 \%$ were employed. In contrast, the employment rate of those without disabilities was $79.8 \%$ (US Bureau of the Census, 1993). In their review of the literature, Wilgosh and Skaret (1987) concluded that employer attitudes are a potential barrier to employment opportunities for people with disabilities. However, this body of research has not been reviewed since 1987 and in the interim the Americans with Disabilities Act (ADA) of 1990 has been enacted. The ADA is the most comprehensive civil rights law protecting individuals with disabilities in employment settings to date.

Dichev (1999) says that rankings of graduate business programs in the United States appear to be an influential factor in the decisions of a variety of interested parties, including business school applicants, alumni, employers, and business school and university administrations. Motivated by the importance of MBA rankings, this study investigates the nature and quality of the two major sources of such rankings, Business Week and U.S. News and World Report (hereafter U.S. News). The main insights of this study derive from an examination and analysis of two key characteristics of the rankings. First, this study investigates the predictability of future changes in the rankings. The motivation is that little or no predictability of future changes implies that current rankings are good forecasts of future rankings. In other words, if current rankings summarize all relevant forecasting information efficiently, then changes in the rankings should be triggered only by new information, which is by definition unpredictable. Forecasting ability is likely to be a key consideration to business school applicants 
because there is a 2-3-year lag between the ranking that determines the applicants' school choice and the ranking that determines the employers' demand for a given school's graduates. Since business school applicants are the most important users of the rankings (especially from a publisher's perspective), it seems useful to investigate the rankings' predictability of changes. Finding substantial predictability in changes allows one to conclude that current rankings are poor forecasts of future rankings. In addition, the potential predictabilities could yield other insights into the rankings. For example, it is possible that current rankings are poor forecasts but they are good measures of contemporaneous business school performance, much like bestseller rankings are often poor forecasts of future sales but are a good indication of contemporaneous sales success. Assuming that rankings capture only contemporaneous performance, a positive autocorrelation in the rankings' changes might be interpreted as evidence of "momentum" or "feedback" effects in business schools' real performance, while a negative autocorrelation might be indicative of "fight back" effects in real performance. Second, this study investigates the timeliness of the rankings. If changes in business school rankings are a timely reflection of real changes in the underlying unobservable "business school quality" or' business school performance," then there should be a considerable positive correlation between the concurrent rankings changes for Business Week and U.S. News.

In contrast, a weak or no-positive cross rankings correlation in changes implies that the two rankings use unrelated information. Using first-order autocorrelation as a proxy for predictability, the first set of tests reveals that the autocorrelation in rankings changes is large and significantly negative (on the magnitude of 20.27 to 20.46) for both Business Week and U.S. News. This result suggests that a large portion of the rankings changes predictably reverses in the future. An additional investigation reveals that the most likely reason for the reversibility in rankings is reversibility or "noise" in the information used in producing the rankings. An examination of the published methodologies reveals that both Business Week and U.S. News rankings are based on simple aggregations of information. It is reasonable to think that the information contains various measurement errors or "noise.' The simple aggregation of information in the rankings implies that the rankings mechanically incorporate this noise as well. Since this measurement error or noise predictably reverses in the future, the published rankings will exhibit reversibility in changes as well.

The second set of tests reveals that the correlation between concurrent changes in Business Week and U.S. News rankings is close to zero, even in the long run. Thus, the cross-rankings correlation results suggest that the two rankings are largely based on different information. Since both rankings seem to reflect relevant information, it appears that neither ranking should be interpreted as a broad measure of school quality and performance. In other words, an absence of positive correlation combined with reversibility in changes implies that one should avoid a broad interpretation of the rankings as measures of the unobservable "school quality," but rather interpret them more narrowly as useful but noisy and incomplete data about school performance. There are a number of possible implications and uses of these results. On the most direct and practical level, the results expand our understanding of business school rankings and could help users of the rankings in pursuing their goals. For example, Business Week and U.S. News can possibly 
use these findings to improve the design of their rankings. As another example, users interested in forecasting future rankings can explicitly discount short-term changes in the rankings to eliminate the reversibility in rankings. On a more methodological level, it is clear that the arguments and tests used in this study can be applied to a variety of other ranking settings. It will be interesting to see whether and how the results for these other settings differ from those identified here.

Soutar (2002) wrote that tertiary education has become more competitive in recent years due to reductions in government funding and higher student fees. As the nature of the environment grows more competitive, the role of marketing, previously nonexistent in most universities, has grown significantly. One of the key pieces of information that would assist a university's marketing effort is an understanding of what determines a student's university preference. Research examines university preference using a form of conjoint analysis, known as adaptive conjoint analysis (ACA), to investigate the importance of a number of attributes to high-school leavers in Australia. Results indicate that the four most important determinants of university preference were course suitability, academic reputation, job prospects, and teaching quality, which have significance for education managers developing marketing strategies and programs.

Cannings (1997) says that previous studies on the determinants of the choice of college major have assumed a constant probability of success across majors or a constant earnings stream across majors. Our model disregards these two restrictive assumptions in computing an idiosyncratic expected earnings variable to explain the probability that a student will choose a specific major among four choices of concentrations. The construction of an expected earnings variable requires information on the student's perceived probability of success, the predicted earnings of graduates in all majors and the student's expected earnings if he (she) fails to complete a college program. Using data from the National Longitudinal Survey of Youth, we evaluate the chances of success in all majors for all the individuals in the sample. Second, the individuals' predicted earnings of graduates in all majors are obtained using regression estimates from a 1987 Survey of Recent College Graduates. Third, we obtain idiosyncratic estimates of earnings alternative of not attending college or by dropping out with a condition derived from our college major decision-making model applied to our sample of college students. Finally, with a mixed multinomial log it and probit models and a heteroscedastic extreme value model, we explain the individuals' choice of a major. The results of the paper show that the expected earnings variable is essential in the choice of a college major. There are, however, significant differences in the impact of expected earnings by gender and race.

Starkey (2007) in his book says that in recent decades, business schools have become important components of higher education throughout the world. Yet, surprisingly, they have received little serious attention. This book provides a sober and evidence-based assessment, charting the history and character of business schools in the light of current debates about the role of universities and the evolution of advanced economies. Previous commentators have viewed business schools as falling between two stools: lacking in academic rigor yet simultaneously derided by the corporate world as broadly irrelevant. However, over-concern with criticism risks ignoring the benefits of reform. What business schools need is reconfiguration based on new relationships with academia and business. 
Such change would deliver institutions that are truly fit for purpose, allowing them to become key players in the 21st century's emergent knowledge societies. This timely critique should be read by academics and policy-makers concerned with the present state and future development of business education"

\section{Methodology}

\subsection{Research Design}

This research is a descriptive research study. Descriptive research involves collecting information about research participants' beliefs, attitudes, interests or behavior through questionnaire. This research is designed to assess the attitudes of undergraduate students, graduate students and corporate world towards leading business schools in Karachi.

\subsection{Data}

This research is based on primary data collected through Questionnaires. We have developed separate Questionnaires for three target segments: students of selected business schools, management of the business schools, and selected corporate organizations in Karachi.

We have chosen locations according to convenience sampling method as we have described that our respondents are from five business schools therefore I visited universities to take input of students through getting the questionnaire filled. Input of business schools and corporate organization was taken into account by circulating the questionnaire to their respective administration/human resource departments. Sample size of three segments including students, management of institutes and corporate organization is as under.

\begin{tabular}{|c|c|c|c|c|c|}
\hline $\begin{array}{c}\text { Corporate } \\
\text { Organizations Input }\end{array}$ & & & & & \\
\hline Organization & Sample & Student Input & & Organization Input & \\
\hline PSO & 1 & Institutes & Size & Institute & Size \\
\hline Bosicor & 1 & IBA & 50 & IBA & 1 \\
\hline AlAbbas Sugar & 1 & CBM & 50 & CBM & 1 \\
\hline JS Investment & 1 & HAMDARD & 50 & HAMDARD & 1 \\
\hline JS Bank & 1 & SZABIST & 50 & SZABIST & 1 \\
\hline MCB & 1 & MAJU & 50 & MAJU & 1 \\
\hline Bank Islami & 1 & Total & 250 & Total & 5 \\
\hline Habib Bank & 1 & & & & \\
\hline G4S SMS Pvt Ltd & 1 & & & & \\
\hline Towlers Pakitan & 1 & & & & \\
\hline Total & 10 & & & & \\
\hline
\end{tabular}




\subsection{Model}

Research model in this study is based on Likert Scale method. A Likert scale is a psychometric scale commonly used in questionnaires, and is the most widely used scale in survey research. When responding to a Likert questionnaire item, respondents specify their level of agreement to a statement. Respondents input are analyzed through weighted averages and weighted average percentage method. Weighted average is an average in which each quantity to be averaged is assigned a weight. These weightings determine the relative importance of each quantity on the average. Weightings are the equivalent of having that many like items with the same value involved in the average.

$$
\begin{aligned}
& \text { WeithedAverage }=\frac{\sum f x}{\sum f} \\
& \text { Where, } \\
& \mathrm{f}=\text { no. of respondents, and } \\
& \mathrm{x}=\text { weight on scale. } \\
& \qquad \begin{array}{l}
\text { WeightedAverage } \%=\frac{\text { Wt.Av. }}{\text { No.of Scale }} * 100
\end{array}
\end{aligned}
$$

\section{Results and Discussion}

Following results are based on the Questionnaires floated to incorporate inputs/feelings of business students, business institutions and the corporate entities respectively. Results discussed below provide three dimensional view of (students, institutes and employers) attitude towards business school.

\subsection{Analysis of Student's Input}

Questionnaire designed for this phase is comprised of nineteen questions including open ended, close ended and rating questions. Student's input is analyzed is two separate parts (1) overall analysis that shows the overall level of satisfaction related to different features of the business schools and in (2) comparative analysis an effort has been made to categorize five business schools on the basis of student's perception. Results incorporated in forthcoming tables are weighted averages showing level of satisfaction of the students with different features of business schools and comparative analysis showing comparative position of five business institutes.

On the basis of survey results shown (table 1.1 to 1.5 ), we can infer following deductions:

a. Administration of institutes needs to further improve upon its quality of service while dealing with student's routine affairs. Also faculty members may review m e th o d of teaching, level of cooperation in the class so as to improve overall quality of education.

b. Indoor games and career counseling facilities may be enhanced to a significant level. Fortification of security measures so as to dilute student's perception about insecure environment. 
c. Students are found to be quite satisfied with fee structure being reasonable. Besides other reasons the ultimate motivation while choosing institute of study is the quality of education been imparted.

d. CBM has earned better grading as compare to other institutes in Karachi for imparting quality education, for having quality faculty and for providing adequate reference material in the library. However they need to improve upon their administrative services being provided to students and the fee structure as it has been graded expensive.

e. $\quad$ IBA is considered to be most inexpensive in terms of fee structure however their rating for administrative support to the students is rated lowest as compare to other institutes. Quality of faculty and quality of education being maintained is considerably low as compare to other institutes in Karachi.

f. Hamdard is considered to be most expensive in terms of fee structure, have reasonable score for providing reference material in library. However score for imparting quality education is considerably low. MAJU has earned fairly satisfactory grading overall from students except fee structure that is graded expensive. Furthermore, it needs improve upon the quality education it imparts.

g. SZABIST has scored comparatively lowest for providing quality education, faculty, and administrative support to the students. However it is considered less expensive as far as fee structure is concerned.

\subsection{Analysis of Business Institution's Input}

Questionnaire designed to take input from business institutes is comprised of thirteen questions and most of the question were close ended as well as rating questions. Administration Departments of five institutes, including IBA, CBM, Hamdard, SZABIST and MAJU was contacted to fill in these Questionnaires. Results incorporated in forthcoming tables are weighted averages of feeling/perception of five institutes of Karachi regarding role of HEC, its grading criterion and its implications on students/parents.

On the basis of survey results mentioned (table 2.1 to 2.2), we can infer following deductions:

a. Business institutes in Karachi are very conscious about their HEC grading and they believe that grading does effect the reputation of institute and students/parents do give significant consideration to grading before taking admission.

b. Business institutes in Karachi opine that grading is healthy activity but they are only partially satisfied with HEC grading criterion. Although most of business institutes have graded themselves higher than their present HEC grading meanwhile they also want to improve quality of education they are imparting. 
c. Business institutes in Karachi do take feedback from students and faculty about HEC grading criterion and they have strongly suggested that HEC should modify grading criterion by conducting surveys.

\subsection{Analysis of Corporate/Employer's Input}

Questionnaire designed to take corporate/employer's input is comprised of ten questions including open ended, close ended and rating questions. Results mentioned below are based on input from ten randomly selected corporations. Corporate/employer's input is analyzed is two separate parts (1) overall analysis that shows general feelings of employers regarding performance of business graduates, selection criterion and their perception about business institutes in Karachi (2) in comparative analysis an effort has been made to categorize five business schools on the basis of corporate/employer's perception. Results incorporated in forthcoming tables are weighted averages showing level of satisfaction of the employers with the performance of business schools and their respective graduates and comparative position of five business institutes.

On the basis of survey results mentioned (table 3.1 to 3.3), we can infer following deductions:

a. Most of Corporate representatives opine that business schools are not seeking fair requirements of skills for business graduates jobs thereby graduates do not fulfill modern business needs. So in order to bridge this vacuum business institutes are required to seek corporate advice while designing academic activities/curricula.

b. Business institutes were found to be effective while imparting leadership qualities in business graduates. Corporate policies for recruitment/hiring business graduate gives high weight to the positive attitude of the candidate, meanwhile significant importance is also given to quality of education the candidate brings in the organization. Although name of the institute does matter a lot during hiring/recruitment but positive attitude and quality education are more dominating variables.

c. Corporate entities in Karachi have given highest grading to the IBA's business graduates for bearing quality education and rest of them have been graded way below. Results clearly shows dominating position of IBA students in corporate regime that can either be because of the extra ordinary instructional methodology or the prime mover advantage of IBA.

d. In contrast to preceding deduction, IBA has been rated to be lowest on the basis of working efficiency of their respective business gradates and MAJU, Hamdard, ZABIST were graded higher in descending order. CBM on this account was rated in between with fairly satisfactory score. 


\section{Conclusion}

Viewing the results of the study we may conclude that quality of education is graded as first priority by the students for taking admission. Viewing the low level of satisfaction students stated that faculty members may review method of teaching and level of cooperation in the class. Students were also found dissatisfied with services of administration staff in business institutes and the existing career counseling facilities. Students further urged to fortify security arrangements at schools as well as to enhance indoor games facilities at the institutions. Students also rated existing fee structure as inexpensive. But students from Hamdard, MAJU and CBM are found dissatisfied due to its demographic profile. CBM is rated high for imparting quality education, for qualified faculty whereas IBA is rated inexpensive and having uncooperative administrative staff.

Business institutes in Karachi are found to be very conscious about their HEC grading as they believe that grading does affect the reputation of institutes. They consider grading of the institute as healthy activity however they are partially satisfied with HEC grading criterion as most of them have graded themselves higher than their present HEC grading. Management of business institutes is found to be wanting and hence need to further improve quality of education. On the basis of feedback from faculty and student, they strongly suggested that HEC should modify grading criterion by conducting surveys.

In order to fulfill modern business needs, most of the corporate organizations have urged business institutions to seek requirements of skills for business graduates jobs. Corporate community has acknowledged leadership qualities found in business graduates. Corporate policies for hiring business graduate are found to be significantly inclined towards the positive attitude and the quality of education the candidate brings in to the organization. Although name of the institute does influence hiring process but positive attitude and quality education are more dominating variable. The research results further show that graduates of IBA are best on account of bearing quality education. On the other hand IBA as a business institute has earned lowest grading viewing the working efficiency of its graduates. CBM is rated in the middle for imparting quality education and working efficiency of its graduates. Graduates of MAJU, Hamdard and SZABIST are rated very high by corporate organization for their respective work efficiency.

\section{Recommendations}

On the basis of the research results, following recommendations are made to improve the overall quality of business education so as to fulfill the modern business needs of present corporate world.

\section{- Infrastructure for Sports and Non-Academic Activities}

Education regulating authorities including HEC may prepare and implement legal framework for standardization of minimum infrastructure for sports, communication centre, computer lab, and library and security facilities at business institutes. 
- Standardization of Fee Structure

In order to streamline perception about fee structure dissimilarity in the minds of students, education regulating authorities may standardize fee structure by setting maximum fee ranges. Furthermore, upward revision of fee structure should be equal to yearly inflation figures released by the State Bank of Pakistan.

- Periodic Revision of Grading Criterion

HEC may review grading criterion of business institutes on regular basis with due consultation of renown educationist in the county, faculty members, students and the management of business institutes as well.

\subsection{Limitations}

Following limitations are observed during this research.

\section{- Limited Market Access}

This research is limited to Karachi only as other geographical areas of Pakistan are not covered.

- Time Constraints

Limited time of eight months was available for collection/analysis of data and compilation of this report. 


\section{References}

Cannings, Kathy. Claude Montmarquette and Sophie Mahseredjian. (April 1997) "How do young people choose college majors?" CIRANO Working Papers, http://ideas.repec.org/p/mt//montec/9719.html

Dichev, Ilia D. (April 1999) "How Good Are Business Schools Rankings". Journal of Business, Vol. 72, No. 2, University of Michigan Press

Gutteridge, Thomas G. (1973) "Predicting Career Success of Graduate Business School Alumni" Academy of Management Journal, Vol.16, No.1, (March) Academy of Management.

Hernandez, Brigida. Christopher Keys and Fabricio Balcazar. (2000) "Employer Attitudes toward Workers with Disabilities and Their ADA Employment Rights" The Journal of Rehabilitation, Vol.66,

Hodges, Dave and Noel Burchell. (2003) "Business Graduate Competencies: Employers' View on Importance and Performance" Asia-Pacific Journal of Cooperative Education, UNITEC Institute of Technology.

Morstain, Barry R. (2010) "Analysis of Students' Satisfaction with their academic program" The Journal of Higher Education, Vol.48, No.1 Jan 1977 Ohio State University Press.

Nettles, Michael T. Erica J. Gosman and A.Robert Thoeny. (1986) "Comparative and Predictive Analyses of Black and White Students' College Achievement and Experiences" The Journal of Higher Education, Vol. 57, No.3 Ohio State University Press.

Oliver, Christine. (1997) "Sustainable Competitive Advantage: Combining Institutional and Resource-Based Views" Strategic Management Journal, Vol.18, No.9, John Wiley \& Sons.

Patterson, Paul G. Lester W. Johnson and Richard A. Spreng. (1996) "Modeling the determinants of customer satisfaction for business-to-business professional services" Journal of the Academy of Marketing Science Vol.25, Number 1, December, The University of New South Wales, Sydney, Australia

Pike, Gary R. (2001) "The effect of background, coursework and involvement of students' grade and satisfaction" Research in Higher Education, Vol.24, Number 3, Spring, The Johns Hopkins University Press.

Scott, Michael G. and Daniel F. Twomey. (2002) "The long-term supply of Entrepreneurs: Students' Career Aspiration in Relation to Entrepreneurship" Economic of Education Review, Vol.21, Issue 6, University of Montreal.

Soutar, Geoffrey N. and Mrs. Julia P. Turner. (2002) "Students' preference for university: a conjoint analysis" International Journal of Educational Management Vol.16, Issue. 1, MCB UP Ltd. 
Starkey, Ken. And Nick Tiratsoo (2007) The Business School and the Bottom Line. London: Cambridge University Press.

Stewart, Jim. and Mr. Vanessa Knowles. (2000) "Graduate recruitment and selection: implications for HE, graduates and small business recruiters" Career Development International Vol.5, Issue 2, MCB UP Ltd. 


\section{Appendix 1}

\section{Table-1.1}

\begin{tabular}{|c|c|l|l|}
\hline & Student's Input & & \\
\hline & Overall Results & & \\
\hline \multicolumn{3}{|c|}{ Student's Level of satisfaction } \\
\hline
\end{tabular}

\begin{tabular}{|c|c|c|}
\hline S/No & Description of Results & Wt. Av. \% \\
\hline 1 & Student's feeling about fee being expensive & 59.1 \\
\hline 2 & Student's feeling about quality of education being imparted & 62.1 \\
\hline 3 & Grading of faculty in term of cooperation, way of teaching and grading & 57.6 \\
\hline 4 & Student's feel about Strictness of administration on attendance in class & 92.2 \\
\hline 5 & Student's feel about availability of reference material in library & 73.4 \\
\hline 6 & Student's input regarding arrangement of extracurricular activities & 71.1 \\
\hline 7 & Student's input regarding provision of career counseling in institutes & 61.6 \\
\hline 8 & Student's input about dealing \& interaction of admin with students & 69.68 \\
\hline 9 & Availability of indoor games in the institution & 51.52 \\
\hline
\end{tabular}

Table 1.2

\begin{tabular}{|c|c|c|}
\hline & Student's Input & \\
\hline \multicolumn{3}{|c|}{ Overall Results } \\
\hline \multicolumn{3}{|c|}{ Rating of institute's features on scale 1 - 5 } \\
\hline S/No & Description of Results & Wt. Av. \% \\
\hline 1 & Administration & 60.56 \\
\hline 2 & Faculty of the institute & 57.04 \\
\hline 3 & Grading of the institute & 57.12 \\
\hline 4 & Academic arrangements & 58.16 \\
\hline 5 & Non academic activities & 58.64 \\
\hline 6 & Library of the institute & 58.08 \\
\hline 7 & Computer Lab & 60.72 \\
\hline 8 & Security arrangements & 54.08 \\
\hline
\end{tabular}


Table 1.3

\begin{tabular}{|c|c|c|}
\hline \multicolumn{3}{|c|}{ Student's Input } \\
\hline \multicolumn{3}{|c|}{ Overall Results } \\
\hline \multicolumn{3}{|c|}{ Student's General Comments } \\
\hline S/No & Description of Results & $\%$ Scores \\
\hline \multirow[t]{5}{*}{1} & Reasons to get admission & \\
\hline & Quality Education & 54 \\
\hline & Couldn't get Admission in other & 19.2 \\
\hline & Suitable Location & 8 \\
\hline & Other reasons & 18.8 \\
\hline \multirow[t]{3}{*}{2} & Satisfaction with grading plan in the Institute & \\
\hline & Yes & 55.2 \\
\hline & No & 44.8 \\
\hline \multirow[t]{4}{*}{3} & Grading Criterion in the institute & \\
\hline & concept only & 10.4 \\
\hline & concept + practical & 9.2 \\
\hline & concept + practical + Presentation & 78.8 \\
\hline \multirow[t]{3}{*}{4} & Conduct of workshops \& Seminars & \\
\hline & Yes & 85 \\
\hline & No & 14 \\
\hline \multirow[t]{3}{*}{5} & Does the institutes provides scholarships & $\%$ Scores \\
\hline & Yes & 88 \\
\hline & No & 11 \\
\hline \multirow[t]{3}{*}{6} & Suggesting others to take admission in yours & \\
\hline & Yes & 66 \\
\hline & No & 28 \\
\hline
\end{tabular}


Table 1.4

\begin{tabular}{|c|c|c|}
\hline \multicolumn{3}{|c|}{ Student's Input } \\
\hline \multicolumn{3}{|c|}{ Overall Results } \\
\hline \multicolumn{3}{|c|}{ Student's General Comments } \\
\hline S/No & Description of Results & $\%$ Scores \\
\hline \multirow[t]{11}{*}{1} & Comments on business institute & \\
\hline & It's Hard to survive there & 3.2 \\
\hline & Its Growing & 1.2 \\
\hline & No comments & 48.8 \\
\hline & Admin should be cooperative & 4 \\
\hline & Its Good & 17.6 \\
\hline & should improve & 10.8 \\
\hline & not good enough & 1.2 \\
\hline & Poor admin & 7.6 \\
\hline & Education is declining & 2.4 \\
\hline & Practical Approach & 3.2 \\
\hline
\end{tabular}

Table 1.5

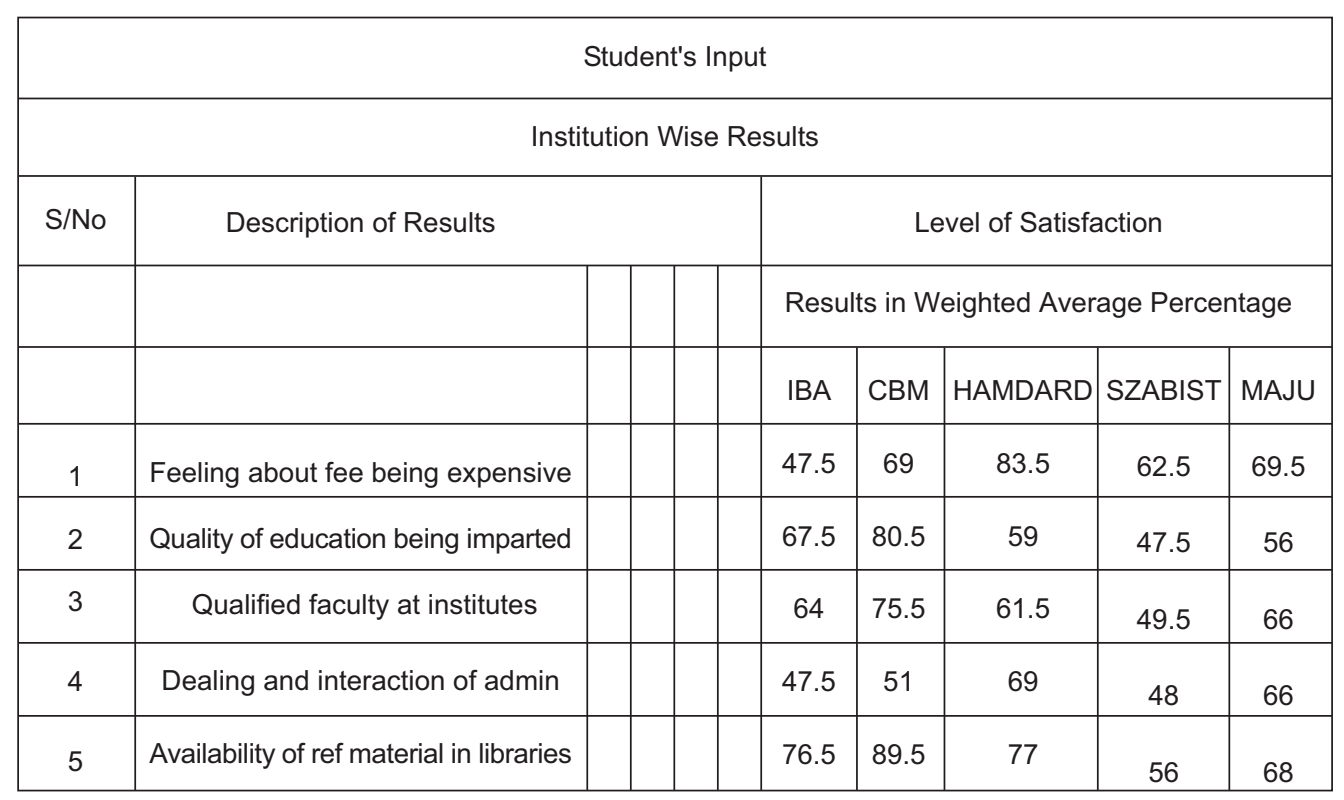




\section{Appidex 2}

\section{Business Institutions Input}

Table 2.1

\begin{tabular}{|c|c|c|c|}
\hline \multicolumn{2}{|c|}{ How to Modify grading system } & & \\
\hline Institute's Input & & Frequency & Percentage \\
\hline Should be modified & 4 & 80 \\
\hline HEC should conduct survey & 1 & 20 \\
\hline Total Input & 5 & 100 \\
\hline
\end{tabular}

Table 2.2

\begin{tabular}{|c|c|l|l|}
\hline \multicolumn{2}{|c|}{ Institution's Input } & \multicolumn{2}{l}{} \\
\hline \multicolumn{2}{|c|}{ Institution's Level of satisfaction } & \multicolumn{2}{c|}{ Wt. Av. \% } \\
\hline S/No & Description of Results & 80 \\
\hline 1 & Where do you grade your institution (no1 - not concern) & 66.7 \\
\hline 2 & Satisfaction with HEC grading criteria? & 73.3 \\
\hline 3 & Guality of education at your institute & 60 \\
\hline 4 & Grading impact on reputation of institute & 67 \\
\hline 5 & Grading impact on the parents & 70 \\
\hline 6 & Grading impact on the students & 73 \\
\hline 7 & Grading effect the student's choice of Institute & 65 \\
\hline 8 & Role of HEC in improving education standard? & 55 \\
\hline 9 & Feedback from faculty regarding HEC grading criteria & 80 \\
\hline 10 & Feedback from students regarding HEC grading criteria & 100 \\
\hline 11 & & 100 \\
\hline 12 & &
\end{tabular}




\section{Apendex 3}

\section{Employer's Input}

Table 3.1

\begin{tabular}{|l|l|l|}
\hline Employer's Input & & \\
\hline Overall Results & & \\
\hline
\end{tabular}

\begin{tabular}{|c|c|c|}
\hline \multicolumn{2}{|c|}{ Employer's Level of satisfaction } & \\
\hline \multicolumn{2}{|c|}{ Description of Results } & \\
\hline Business schools seeks requirement of skills for job for business students & Wt Avg \% \\
\hline Business schools fulfill requirement of modern business needs & 60 \\
\hline Attitude of business graduates effect environment of firm & 63 \\
\hline Business schools are producing business leaders of tomorrow & 60 \\
\hline Name of institute matters in hiring process & 76 \\
\hline
\end{tabular}


Table 3.2

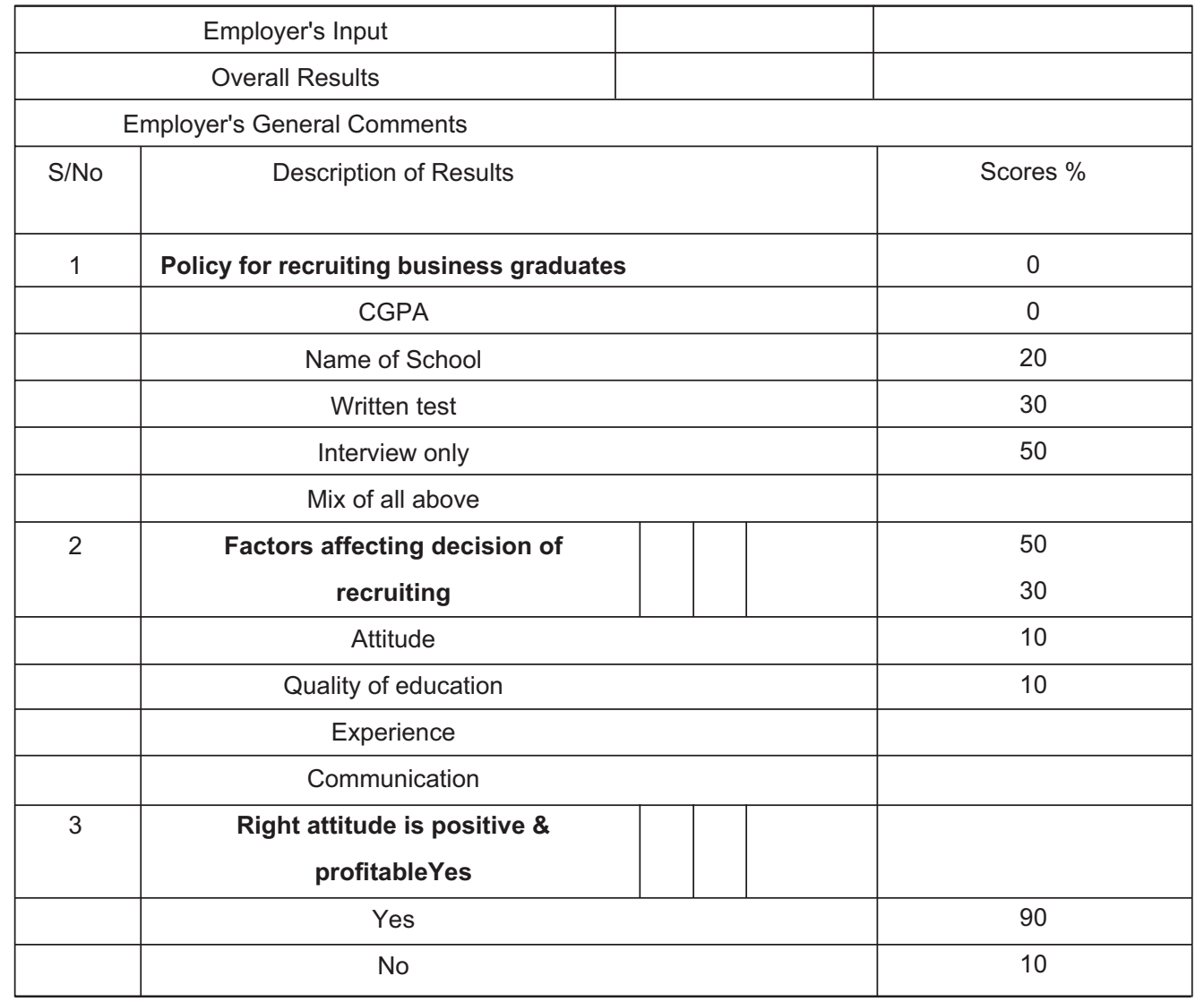

Table 3.3

\begin{tabular}{|l|r|c|c|c|r|}
\multicolumn{2}{|c|}{} & \multicolumn{4}{|c|}{ Level of Satisfaction } \\
\cline { 2 - 6 } \multicolumn{2}{|c|}{} & \multicolumn{3}{|c|}{ Weighted Average Percentage } \\
\hline Description of Results & IBA & CBM & HAMRD & ZABIST & MAJU \\
\hline Categorization of business graduates for their quailty of education & 88 & 20 & 14 & 17 & 11 \\
\hline Ranking of schools in terms of working effeciency of business graduates & 28 & 50 & 72.5 & 72.5 & 80 \\
\hline
\end{tabular}

